\title{
Foco na formação
}

Recebido em 26.12.2012. Aprovado em 28.12.2012 Avaliado pelo sistema double blind review

\section{Heliana Battaglia Beltrame}

helianabeltrame@gmail.com

SESI de Americana - Americana- SP - Brasil.

\section{Resumo}

A Rede SESI de São Paulo prima pela qualidade no atendimento aos alunos nas suas unidades escolares. Buscando um acompanhamento mais próximo do desempenho de cada escola, promoveu uma reestruturação implantando treze Supervisões Estratégicas de Atendimento, distribuídas por várias regiões do Estado de São Paulo.

A Supervisão Estratégica de Atendimento de Americana, a partir de vários levantamentos diagnósticos realizados nas unidades pertencentes a sua regional, propõe a realização de um projeto formativo denominado FOCO NA FORMAÇÃO, visando melhorar o acompanhamento pedagógico das Coordenadoras junto às equipes das unidades escolares. Propõe também a formação continuada e 0 acompanhamento dos professores a partir das necessidades detectadas. Pretende com essa ação, elevar os resultados dos alunos, melhorando o seu nível de aprendizagem.

Tendo os objetivos bem definidos, as estratégias muito bem planejadas, o projeto traz possibilidades que impactarão de forma bastante positiva nos resultados das unidades que serão atendidas, resultando na qualidade almejada pelas equipes, pelos membros da Supervisão Estratégica e pela entidade.

Palavras-chaves: Formação continuada. Acompanhamento pedagógico. Resultados. Aprendizagem. 


\section{Contexto da supervisão estratégica de atendimento - SESI de Americana}

\section{Breve Histórico}

O Serviço Social da Indústria - SESI foi criado pelo Decreto lei $n^{0} 9.403$, de 25 de junho de 1945 e regulamentado pelo Decreto $n^{0} 57.375$, de 2 de dezembro de 1965. É uma entidade jurídica de direito privado, com sede e foro na capital da República, organizado e dirigido pela Confederação Nacional da Indústria CNI.

O Departamento Regional de São Paulo - SESI SP, orgão central de administração da sua rede escolar, com base territorial do Estado, mantém e supervisiona as escolas que oferecem educação básica, educação profissional e educação de jovens e adultos.

A rede SESI - SP possui 175 Centros Educacionais espalhados por todo o Estado.

Tem como Missão promover a qualidade de vida do trabalhador e de seus dependentes, com foco em educação, saúde e lazer, e estimular a gestão socialmente responsável da empresa industrial.

Tem como Visão ser líder nacional na promoção da melhoria da qualidade de vida do trabalhador e de seus dependentes e da gestão socialmente responsável.

Primando pela qualidade do ensino e considerando a dimensão da rede SESI - SP de ensino e suas características e peculiaridades, o modelo de apoio à gestão das unidades e formação até então estabelecido, atendia a uma necessidade que já não correspondia mais às demandas e necessidades da realidade atual, exigindo uma nova forma de pensar, agir e gestar os processos educacionais e formativos existentes.

Desta forma, em 28/08/2012, por meio da Resolução RE 29/12, a Divisão de Educação do SESI - SP foi reestruturada, propondo a criação de 13 Supervisões Estratégicas de Atendimento com o objetivo de descentralizar processos e ações e aproximar equipes de apoio às Unidades Escolares.

A equipe de cada Supervisão Estratégica de Atendimento, composta por Supervisor Técnico Educacional, Analistas Técnicos Educacionais, Auditor em Educação, Especialista em Educação passa a ter a finalidade de proporcionar processos de formação continuada de docentes e profissionais da educação. Por meio do diagnóstico das necessidades formativas, a Supervisão Estratégica de Atendimento tem a responsabilidade de promover ações e suporte à gestão escolar e prática docente que impactem na melhoria da aprendizagem de todos os alunos.

\section{Caracterização da supervisão estratégica de atendimento de americana}

A Supervisão Estratégica de Atendimento de Americana está instalada em uma sala do Centro Educacional SESI 101, em Americana - São Paulo.

A equipe da SEA é composta por um Supervisor Técnico Educacional, um Auditor em Educação, um Especialista em Educação e quatro Analistas Técnicos Educacionais, atuando nas seguintes áreas: $1^{\circ}$ ao $5^{\circ}$ anos, Linguagens, Ciências Humanas, Ciências da Natureza e Matemática.

Essa equipe faz o acompanhamento das seguintes unidades escolares do SESI: Centro Educacional 099 de Santa Bárbara d'Oeste, Centro Educacional 101 de Americana, Centro Educacional 299 de Valinhos, Centro Educacional 341 de Sumaré, Centro Educacional 389 de Valinhos, Centro Educacional 403 de Campinas, Centro Educacional 404 de Campinas, Centro Educacional 420 de Indaiatuba, Centro Educacional 421 de Campinas, Centro Educacional 422 de Americana, Centro Educacional 436 de Nova Odessa e Centro Educacional 437 de Hortolândia.

Dados sobre as Unidades Escolares pertencentes à SEA de Americana: 
Tabela 1

Estrutura física das Unidades Escolares

\begin{tabular}{|c|c|c|c|c|c|c|c|c|c|}
\hline \multicolumn{10}{|c|}{ Salas } \\
\hline Escola & Aula & Multi & $\begin{array}{l}\text { Vivên } \\
\text { cias }\end{array}$ & Música & $\begin{array}{l}\text { Vivência e } \\
\text { Tecnologia }\end{array}$ & Física & $\begin{array}{c}\text { Químic } \\
\text { a }\end{array}$ & $\begin{array}{c}\text { Bibliote } \\
\text { ca }\end{array}$ & Quadra \\
\hline CE 099 & 20 & --- & --- & --- & 1 & --- & --- & 1 & $\begin{array}{l}1 \text { aberta } \\
2 \text { coberta }\end{array}$ \\
\hline CE 101 & 18 & 1 & $\begin{array}{c}1 \\
\text { Teatra } \\
\text { is }\end{array}$ & 1 & 1 & 1 & 1 & 1 & 1 coberta \\
\hline CE 299 & 12 & $\begin{array}{c}1 \\
\text { mat.p } \\
\text { ed. }\end{array}$ & $\begin{array}{c}1 \text { Arte } \\
1 \\
\text { Vídeo }\end{array}$ & --- & $\begin{array}{c}1 \text { Lego } \\
1 \\
\text { Informática }\end{array}$ & --- & $\begin{array}{c}1 \\
\text { Ciência } \\
\text { s }\end{array}$ & 1 & $\begin{array}{l}1 \text { aberta } \\
1 \text { coberta }\end{array}$ \\
\hline CE 341 & 18 & 1 & --- & --- & 1 & $\begin{array}{c}1 \\
\text { Fis/Qui/ } \\
\text { Bio }\end{array}$ & --- & 1 & $\begin{array}{l}1 \text { aberta } \\
1 \text { coberta } \\
1 \text { areia } \\
1 \text { rugby }\end{array}$ \\
\hline CE 389 & 18 & $\begin{array}{c}1 \\
\text { jogos } \\
\text { I multi }\end{array}$ & --- & ---- & $\begin{array}{c}1 \\
\text { Informática }\end{array}$ & --- & ---- & 1 & $\begin{array}{c}1 \text { aberta } \\
1 \text { coberta } \\
1 \text { jogos manuais }\end{array}$ \\
\hline CE 403 & 11 & --- & --- & --- & $\begin{array}{c}1 \text { Lego } 1 \\
\text { Informática }\end{array}$ & --- & --- & --- & $\begin{array}{l}1 \text { aberta } \\
1 \text { coberta }\end{array}$ \\
\hline CE 404 & 12 & --- & --- & ---- & $\begin{array}{c}1 \text { Lego } \\
\text { 1lnformátic } \\
\text { a }\end{array}$ & --- & --- & ---- & $\begin{array}{l}1 \text { aberta } \\
1 \text { coberta }\end{array}$ \\
\hline CE 420 & 24 & 1 & --- & --- & $\begin{array}{c}1 \\
\text { Laboratório }\end{array}$ & ---- & --- & 1 & $\begin{array}{c}2 \text { aberta } \\
2 \text { descobertas }\end{array}$ \\
\hline
\end{tabular}




\begin{tabular}{|c|c|c|c|c|c|c|c|c|c|}
\hline CE 421 & 24 & --- & --- & --- & $\begin{array}{c}1 \text { Lego } \\
\text { 1Informátic } \\
\text { a }\end{array}$ & -.-- & --- & 1 & $\begin{array}{l}1 \text { aberta } \\
1 \text { coberta }\end{array}$ \\
\hline CE 422 & 15 & 1 & --- & --. & $\begin{array}{c}1 \\
\text { Informática }\end{array}$ & -.-. & ---. & 1 & 2 cobertas \\
\hline CE 436 & 12 & $\begin{array}{c}1 \\
\text { jogos } \\
\text { pedag }\end{array}$ & $\begin{array}{c}1 \\
\text { Ciênci } \\
\text { a e } \\
\text { Tec. } \\
\text { (Lego } \\
\text { ) }\end{array}$ & -.- & 1 & -.- & --- & 1 & 1 aberta \\
\hline CE 437 & 19 & 1 & 1 & 1 & $\begin{array}{c}1 \text { Lego } 2 \\
\text { Informática } \\
1 \text { Ciênc. } \\
\text { Tec. }\end{array}$ & 1 & 1 & 1 & $\begin{array}{c}1 \text { coberta } \\
1 \text { campo society }\end{array}$ \\
\hline
\end{tabular}

Fonte: Escolas SESI São Paulo

Tabela 2

Turmas das Unidades Escolares

\begin{tabular}{l|c|c|c} 
Escola & Ensino Fundamental & Ensino Médio & EJA \\
\hline CE 099 & 19 & 05 & 07 \\
\hline CE 101 & 19 & 04 & 04 \\
\hline CE 299 & 20 & 04 & 02 \\
\hline CE 341 & 14 & 05 & 05 \\
\hline CE 389 & 16 & 03 & 02 \\
\hline CE 403 & 08 & 07 & 09 \\
\hline CE 404 & 12 & 06 & 04 \\
\hline CE 420 & 22 & 06 & 05 \\
\hline CE 421 & 24 & $-\cdots$ & 04 \\
\hline CE 422 & 19 & 03 & 02 \\
\hline CE 436 & 09 & 06 & 02 \\
\hline CE 437 & 18 & 03 & -
\end{tabular}

Fonte: Escolas SESI São Paulo 
Tabela 3

Funcionários das Unidades Escolares

\begin{tabular}{|c|c|c|c|c|c|c|}
\hline Escola & $\begin{array}{l}\text { Administrador } \\
\text { Escolar }\end{array}$ & $\begin{array}{l}\text { Coordenador } \\
\text { Pedagógico }\end{array}$ & Professores & $\begin{array}{l}\text { Auxiliar } \\
\text { Docente }\end{array}$ & Inspetores & Estagiários \\
\hline CE 099 & 01 & 02 & 40 & 01 & 04 & 09 \\
\hline CE 101 & 01 & 02 & 37 & 01 & 04 & 04 \\
\hline CE 299 & 01 & 02 & 33 & 02 & 03 & -- \\
\hline CE 341 & 01 & 02 & 30 & 01 & 04 & 06 \\
\hline CE 389 & 01 & 01 & 26 & 01 & 01 & -- \\
\hline CE 403 & 01 & 02 & 20 & 02 & 03 & 02 \\
\hline CE 404 & 01 & 01 & 32 & 01 & 03 & -- \\
\hline CE 420 & 01 & 02 & 42 & 03 & 04 & 06 \\
\hline CE 421 & 01 & 03 & 35 & 03 & 05 & 08 \\
\hline CE 422 & 01 & 02 & 36 & 02 & 04 & 07 \\
\hline CE 436 & 01 & 02 & 22 & 02 & 03 & 05 \\
\hline CE 437 & 01 & 02 & 32 & 02 & 04 & 06 \\
\hline
\end{tabular}

Fonte: Escolas SESI São Paulo

Em suas atividades iniciais, a Supervisão Estratégica concentrou sua ação na elaboração de um diagnóstico preliminar das Unidades Escolares, buscando identificar seus pontos fortes e aspectos indicados para melhoria. Para o levantamento destes dados foram utilizados alguns instrumentos de pesquisa como questionários aos professores e entrevistas com os gestores, além do contato com cada escola, conhecendo desde sua localização, até particularidade do trabalho dos gestores, professores, funcionários e alunos.

Pela análise realizada foi possível perceber uma grande diversidade nas unidades em termos de estrutura física, na gestão do Administrador que se reflete no cotidiano da unidade e no próprio trabalho também do Coordenador Pedagógico, sendo alguns já mais estruturados e outros ainda a serem construídos. Identificado que há um número grande de Coordenadores ingressantes nessa região, o que demanda um acompanhamento diferenciado. 


\section{Identificação da oportunidade}

Temos hoje uma realidade que deu origem a uma nova forma de entender o conhecimento e o seu ensino e isso demanda profissionais da educação críticos e transformadores diante dessas aceleradas mudanças sociais, das novas configurações do mundo e das novas exigências de aprendizagem.

Segundo Pozo (1996) temos uma nova cultura da aprendizagem que se caracteriza por três aspectos: a explosão da informação, a multiplicação e a diversificação das formas de saber e conhecer e a demanda por uma educação continuada permanente.

Tudo isso se reflete na escola, em suas metas e métodos, nas formas de organizar o trabalho e nas relações existentes entre estudantes, professores e gestores.

A instituição escolar não pode estagnar, deve interagir com as transformações ocorridas, no mundo e no ambiente que a rodeia. Deve entrar na dinâmica atual marcada pela abertura, pela interação e pela flexibilidade.

A educação de qualidade é uma busca constante do SESI - SP, para que isso se torne realidade são necessárias ações que sustentem o trabalho em equipe. Analisando o trabalho dos gestores das unidades, verificamos que muitas são as demandas burocráticas, emergenciais e de toda ordem de problemas do cotidiano que permeiam o dia a dia escolar e essa busca só terá os resultados esperados se 0 trabalho for realizado de forma planejada e bem estruturada. Nesse aspecto percebe-se que as equipes gestoras das unidades necessitam de apoio para que consigam se organizar melhor.

Analisando também os resultados das escolas acompanhadas pela equipe da SEA de Americana, verifica-se a necessidade de melhorias quando se constata ainda muitos alunos com desempenho classificados nos níveis abaixo do básico ou básico, conforme demonstrado, por exemplo, no quadro abaixo.

Tabela 4

Resultados de Matemática $9^{\circ}$ ano - SARESP 2012

\begin{tabular}{l|l|l|l|l|l} 
Centro Educacional & Média & $\begin{array}{l}\text { Alunos no } \\
\text { nível abaixo } \\
\text { do básico }\end{array}$ & $\begin{array}{l}\text { Alunos nósico } \\
\text { bo }\end{array}$ & $\begin{array}{l}\text { Alunos no } \\
\text { nível adequado }\end{array}$ & $\begin{array}{l}\text { Alunos no nível } \\
\text { avançado }\end{array}$ \\
\hline $\mathbf{0 9 9}$ & 296,2 & $1,1 \%$ & $48,3 \%$ & $42,5 \%$ & $8,0 \%$ \\
\hline $\mathbf{1 0 1}$ & 305,9 & $4,3 \%$ & $33,3 \%$ & $47,3 \%$ & $15,1 \%$ \\
\hline $\mathbf{2 9 9}$ & 286,7 & $10,5 \%$ & $48,4 \%$ & $34,0 \%$ & $7,2 \%$ \\
\hline $\mathbf{3 4 1}$ & 314,4 & $0,0 \%$ & $37,1 \%$ & $38,7 \%$ & $24,2 \%$ \\
\hline $\mathbf{3 8 9}$ & 294,1 & $9,3 \%$ & $37,0 \%$ & $44,4 \%$ & $9,3 \%$ \\
\hline $\mathbf{4 0 3}$ & 296,7 & $8,3 \%$ & $45,0 \%$ & $33,3 \%$ & $13,3 \%$ \\
\hline $\mathbf{4 0 4}$ & 295,0 & $4,3 \%$ & $51,1 \%$ & $34,0 \%$ & $10,6 \%$
\end{tabular}




\begin{tabular}{l|l|l|l|l|l}
$\mathbf{4 2 0}$ & 321,6 & $1,0 \%$ & $29,7 \%$ & $42,6 \%$ & $26,7 \%$ \\
\hline $\mathbf{4 2 1}$ & 287,4 & $12,7 \%$ & $42,9 \%$ & $36,5 \%$ & $7,9 \%$ \\
\hline $\mathbf{4 2 2}$ & 314,2 & $3,1 \%$ & $29,7 \%$ & $51,6 \%$ & $15,6 \%$ \\
\hline $\mathbf{4 3 6}$ & 281,6 & $6,7 \%$ & $60,0 \%$ & $33,3 \%$ & $0,0 \%$ \\
\hline $\mathbf{4 3 7}$ & 291,9 & $6,3 \%$ & $43,8 \%$ & $50,0 \%$ & $0,0 \%$
\end{tabular}

Fonte: Escolas SESI São Paulo

Diante das análises realizadas, foi possível estabelecer uma visão geral das escolas da SEA quanto às necessidades dos docentes e dos Coordenadores Pedagógicos, percebendo-se a necessidade de um Projeto Formativo que engloba ações de formação continuada articuladas à realidade das unidades e coordenadas pela Supervisão Estratégica de Atendimento, visando melhorias na qualidade de ensino e consequentemente nos resultados da aprendizagem dos alunos.

Em relação à gestão pedagógica, após as entrevistas com todos os Coordenadores Pedagógicos, foi possível delinear algumas características, mesmo que preliminares, de cada Centro Educacional, apontando para algumas necessidades que necessitam ser supridas.

Observado que de maneira geral a maioria dos Coordenadores Pedagógicos realizam as ações previstas para o cargo, porém necessitam de aprimoramento. As maiores dificuldades estão relacionadas à criação de rotina de estudos para sua própria formação e formação dos professores e na elaboração de registros reflexivos, para as devolutivas que possibilitem intervenções que produzam melhoria nas práticas docentes. Fica evidente também que esse profissional concentra muitas outras atribuições, o que faz com que grande parte deixe de priorizar as demandas formativas, para atender demandas de ordem administrativas, deixando muitas vezes o pedagógico para segundo plano. Criar a identidade profissional do coordenador, torna-se imprescindível nesse projeto formativo, uma vez que ele tem possibilidade de se perceber como real formador da sua equipe docente.

Através dos questionários aplicados junto aos professores e do trabalho realizado pelos Analistas Técnicos nas unidades, onde colocando-se à disposição das equipes para diálogos com professores, seja para contato com suas práticas ou para abordagem de suas dificuldades, puderam ser percebidas ainda, as seguintes necessidades dos docentes: dificuldades na execução de algumas atividades do material didático; necessidade de apoio para trabalho com estudantes com necessidades educacionais especiais (inclusão), necessidade de ampliação do uso do Laboratório de Ciência e Tecnologia, dificuldades para o trabalho com a avaliação formativa e metodologias de ensino, interesse em melhorar o trabalho com a pesquisa na escola. Perceberam-se também dificuldades decorrentes de logísticas e combinados das unidades, as quais decorriam das diferentes organizações e gestões.

Diante da situação exposta criou-se o Projeto "FOCO NA FORMAÇAO" para ser desenvolvido com os Coordenadores Pedagógicos e docentes das unidades pertencentes à SEA de Americana.

O Supervisor Técnico é o profissional que coordenará esse projeto formativo e para isso deverá propor ações articuladas entre si e que atendam aos diferentes profissionais numa perspectiva de formação sistêmica, na qual se possa oferecer a todos os envolvidos melhores condições de atuação, reflexão e transformação do trabalho realizado na escola.

FOCO NA FORMAÇÃO é uma metodologia que favorece o desenvolvimento das competências profissionais de todos os atores envolvidos, promovendo o desenvolvimento da autonomia e reflexão permanente sobre as 
práticas educacionais, de maneira que cada um possa contribuir do seu lugar, em prol de uma meta compartilhada: aprendizagem dos alunos.

Desta forma, o Supervisor Técnico é o responsável por realizar a formação com os Coordenadores Pedagógicos, sendo este 0 agente transformador no âmbito educacional dos processos que convergem para a formação docente, considerando que a mesma irá possibilitar uma melhor organização do trabalho, 0 acompanhamento pedagógico eficiente e eficaz e foco para alcance dos resultados esperados.

Os Analistas Técnicos Educacionais são os responsáveis pela realização da formação continuada com os docentes, conseguindo assim abranger os assuntos com maior especificidade e propriedade nos conteúdos das diferentes áreas de conhecimento.

\section{Caracterização do processo formativo a ser implantado}

O projeto FOCO NA FORMAÇÃO será implantado tendo o Supervisor Técnico como profissional que estará à frente do processo formativo a que ele se propõe. Para isso, coordenará as ações formativas voltadas e que atendam aos diferentes profissionais da SEA de Americana e Unidades Escolares a ela vinculadas:

- Coordenadores pedagógicos

- Analistas Técnicos Educacionais

- Professores.

\section{Coordenadores Pedagógicos}

A formação continuada dos Coordenadores Pedagógicos será realizada pelo Supervisor Técnico Educacional, podendo este contar com a colaboração dos Analistas Técnicos Educacionais em assuntos específicos.

\section{Objetivos:}

- Reconhecer a importância do Coordenador pedagógico como agente articulador da construção coletiva da Proposta Pedagógica da escola e da Rede SESI - SP.

- Desenvolver as competências dos Coordenadores pedagógicos para que possam atuar no acompanhamento das práticas docentes, realizando intervenções que resultem em melhorias na aprendizagem dos educandos.

\section{Resultados esperados:}

- Planejamento e execução de uma rotina que contemple proposições do Plano de Trabalho do Coordenador Pedagógico, abandonando uma prática improvisada e que somente atende às demandas do dia a dia da escola.

- Definição de metas de acompanhamento no que se refere à observação de aulas dos professores, análise dos materiais dos estudantes, estabelecendo períodos e entendendo que deve ser um trabalho sistemático e não pontual.

- Construção de roteiro de observação de aula, baseado nas condições que o professor precisa garantir para possibilitar as aprendizagens declaradas com os objetivos de cada aula.

- Construção de rol de critérios indicativos da ação pedagógica do professor necessária para a aprendizagem dos estudantes e que podem ser analisados através da observação dos materiais dos educandos e dos registros dos docentes (planejamentos, diários de classe, relatórios). 
- Realização de mapeamento e análise do rendimento escolar dos estudantes, para que possam ser pensadas ações que visem 0 aprimoramento das condições de aprendizagem que precisam ser garantidas.

- Identificação dos aspectos da ação do professor que estão adequados e em quais há necessidades de ações formativas para o seu aprimoramento (didáticas dos componentes curriculares e os procedimentos metodológicos).

- Organização dos dados das aprendizagens a partir das produções discentes de forma a realizar intervenções de maneira objetiva com o docente contribuindo com a melhoria dos resultados da aprendizagem.

- Definição de prioridades de atuação em função do que mais compromete as aprendizagens dos estudantes, com o estabelecimento de objetivos a curto, médio e longo prazo, articulados ao seu Plano de Trabalho e ao Plano de Gestão da unidade.

- Elaboração de projeto formativo a partir do diagnóstico e dos objetivos traçados.

- Reconhecimento da necessidade da utilização de subsídios teóricos e práticos para o desenvolvimento de ações formativas, com estratégias formativas que façam sentido para os docentes.

- Compreensão da necessidade de estudos para sua auto formação bem como para seu grupo de professores, identificando em quais aspectos há necessidade de aprimoramento e articulando com os objetivos propostos nas ações formativas.

- Realização das intervenções necessárias para a melhoria das práticas pedagógicas na unidade em que atua, sabendo atuar em parceria com os docentes e administradores escolares, mantendo relacionamento profissional e respeitoso.

- Planejamento de reuniões com os pais de forma a envolver as famílias no processo de aprendizagem dos estudantes.

- Realização de devolutivas reflexivas, por escrito e oralmente, aos docentes, que contribuam efetivamente para o aprimoramento de sua prática, garantindo sempre o apontamento de pelo menos um aspecto positivo.

- Estabelecimento de indicadores que ajudem a explicitar os aspectos da prática do professor que estão sendo tratados em ações formativas, para poder avaliar se as mesmas estão resultando no aprimoramento pretendido (monitoramento).

- Compreensão da necessidade de realização de registros reflexivos de sua própria prática que favoreçam o planejamento de novas ações.

\section{Ações:}

Realizar reuniões para:

- Estudos - Apresentação e reflexão sobre a fundamentação teórica.

- Definição de metas de acompanhamento da prática docente.

- Construções coletivas: roteiro de observação de aula e rol de critérios para análise de materiais de alunos, plano docente, diários de classe.

- Tematização coletiva da prática dos Coordenadores pedagógicos.

- Socialização de boas práticas.

- Construção de indicadores para monitoramento da ação formativa do Coordenador Pedagógico. 
Analisar os roteiros e rol de critérios elaborados e realizar intervenções para melhorias.

Verificar o planejamento de rotina de acompanhamento através de solicitação de encaminhamento das mesmas.

Verificar o acompanhamento da prática docente (análise de projetos formativos, devolutivas, atas).

Tematizar de forma individual a prática dos Coordenadores pedagógicos. Analisando teoricamente as situações práticas - trabalho reflexivo sobre a prática, onde a teoria tem lugar para servir de confronto, afirmação e elucidação das questões cotidianas.

Monitorar o trabalho do Coordenador pedagógico através de análise dos registros reflexivos de sua prática e também dos resultados das aprendizagens da escola.

Apresentar novas referências teóricas.

Produzir documentação de caráter formativo para posterior socialização.

\section{Analistas Técnicos Educacionais}

A formação continuada dos Analistas Técnicos Educacionais será realizada pelo Supervisor Técnico Educacional.

\section{Objetivo:}

- Desenvolver as competências dos Analistas Técnicos Educacionais para que possam atuar na formação dos docentes e no acompanhamento de suas práticas, realizando intervenções que resultem em melhorias na aprendizagem dos educandos.

\section{Resultados esperados:}

- Ampliação do repertório teórico de forma que possam atuar de forma eficaz, buscando embasamento de suas ações e intervenções junto aos docentes, em documentos que são diretrizes para a rede e outras referências que sirvam de subsídio para a reflexão.

- Realização de diagnósticos, levantando as necessidades formativas dos docentes das diferentes unidades escolares.

- Elaboração e execução de plano de formação, tendo claros objetivos e resultados esperados.

- Organização de roteiro de trabalho para atendimento às unidades escolares, de acordo com as necessidades detectadas.

- Realização de intervenções que possibilitem reflexões aos docentes e melhorias em sua prática.

- Elaboração de relatórios e devolutivas com dados significativos com vistas à melhoria das aulas.

- Conhecimento dos resultados das avaliações interna/externa das escolas jurisdicionadas e das metas e ações já estabelecidas.

- Identificação dos aspectos prioritários para a elevação dos resultados de aprendizagem.

- Incentivo e apoio na elaboração de propostas de melhoria da qualidade de ensino, com base na análise dos indicadores, verificando sua adequabilidade.

- Análise da cultura do ambiente escolar das unidades.

- Conhecimento e domínio das atribuições, saberes necessários e perfil do Analista Técnico Educacional e demais profissionais da educação. 


\section{Ações:}

Realizar estudos individuais (auto formação) e coletivos para aprofundamento da fundamentação teórica.

Definir metas de acompanhamento da prática docente.

Construir formulários: roteiro de observação de aula, coleta de dados, planejamento, etc.

Socializar boas práticas.

Construir indicadores para monitoramento da ação formativa.

Tematizar práticas formativas. Análise teórica de situações práticas - trabalho reflexivo sobre a prática, onde a teoria tem lugar para servir de confronto, afirmação e elucidação das questões cotidianas.

Produzir documentação de caráter formativo para posterior socialização.

Observar e avaliar de forma criteriosa o desempenho dos diferentes profissionais.

Buscar cursos em instituições externas que atendam às necessidades de formação.

\section{Docentes}

A formação continuada dos docentes será realizada pelo Coordenador Pedagógico e pelos Analistas Técnicos Educacionais.

\section{Objetivo:}

Proporcionar aos professores subsídios para a melhoria da prática docente e ampliação dos níveis de desempenho dos alunos nas avaliações internas e externas, tendo como base material didático do SESI- SP e a metodologia e didática das áreas.

\section{Resultados esperados:}

- Elaboração de planejamento que atenda às diretrizes curriculares e metodológicas do SESI - SP.

- Prática pedagógica pautada nos procedimentos metodológicos definidos pela rede.

- Aprofundamento de estudos com relação à didática da sua área de docência.

- Análise do rendimento escolar dos estudantes, para que possam ser pensadas ações que visem 0 aprimoramento das condições de aprendizagem que precisam ser garantidas.

- Definição de prioridades de atuação em função do que mais compromete as aprendizagens dos estudantes, com o replanejamento de suas aulas de forma a tender às necessidades de todos.

\section{Ações:}

Estabelecer diálogos, procurando identificar as necessidades formativas dos docentes das diferentes unidades escolares.

Aprofundar estudos das diretrizes curriculares/ metodológicas da Rede SESI - SP, articulado à prática docente e de acompanhamento pedagógico desenvolvida na unidade escolar.

Acompanhar in-loco a execução das atividades docentes, elegendo prioridades. Esse trabalho envolve: acompanhados;

a. Elaboração de cronograma de atendimento mensal, explicitando os professores que serão

b. Contato prévio com os professores, de modo que possa ter ciência do seu plano de aula, e ao mesmo tempo explicitar seu foco de acompanhamento;

c. Elaboração de pauta de observação, com foco nas estratégias didáticas específicas da área 
utilizadas pelo docente;

d. Observação em sala de aula, com registro reflexivo das estratégias didáticas utilizadas pelo professor, que 0 auxiliem a repensar sua prática;

e. Devolutiva oral do acompanhamento, questionando o docente e realizando intervenções assertivas;

g. Atuação em parceria com o docente, dividindo o espaço da sala de aula;

h. Preenchimento do registro de atendimento encaminhando ao Supervisor Técnico Educacional.

Organizar momentos de estudos tendo como referências as diretrizes curriculares/ metodológicas da Rede SESI - SP e outras, visando o aprimoramento da prática dos docentes.

Propor programas de capacitação e ações formativas específicas, visando atender as necessidades formativas da Supervisão Estratégica de Atendimento.

Socializar boas estratégias didáticas utilizadas pelos professores nas escolas da Supervisão Estratégica, em demais atendimentos ou em cursos de formação.

Elaborar junto aos Analistas Técnicos, plano diferenciado de atendimento aos docentes das unidades escolares com resultados mais críticos.

A formação continuada dos professores nos anos de 2014 e 2015 será realizada pelos Analistas Técnicos Educacionais, sendo estruturada de forma a contemplar momentos coletivos com todos os docentes e grupos específicos para atender à diversidade das diferentes unidades.

Serão programados momentos de discussão, para que os Analistas possam conduzir as reflexões a partir de assuntos que foram escolhidos a partir das demandas das unidades, levantadas através de pesquisas e dos acompanhamentos realizados.

Esses momentos deverão ser previstos em calendário escolar, em dias não letivos.

Abaixo estão relacionados os temas que serão tratados:

- Revisitando a concepção de ensino e opção metodológica da Rede SESI - SP

- Material didático do SESI SP - Da concepção à superação de desafios

- Planejamento docente

- Aprendizagem pela pesquisa

- Relação professor e aluno e o contrato pedagógico

- O trabalho com habilidades e competências - Revisitando a matriz de referência

- Avaliação formativa

- Utilização das TICs na Educação contemporânea

\section{Estratégia de implementação}

Análise SWOT

\section{Oportunidades}

Grande valorização do meio acadêmico para a formação continuada.

Projetos institucionais e formação oferecida pela Rede SESI.

Escolas estarem demandando formação.

Falta de profissionais qualificados no mercado, devido ao desinteresse da nova geração pela carreira do magistério.

Mudanças no perfil do aluno da atualidade, que requer dos professores novas habilidades e competências para a condução das aulas. 


\section{Ameaças}

Confusão entre os papeis da família e da escola referentes à educação dos alunos.

Falta de conhecimento sobre a legislação específica para o setor.

\section{Forças}

Atendimento às necessidades específicas das Unidades Escolares.

Localização estratégica do local de formação.

Credibilidade no trabalho.

Profissionais com qualificação, comprometimento e motivação.

Gestão compartilhada e possibilidade de diálogo para resolução de problemas.

Ambiente de trabalho agradável.

Preocupação com a melhoria da qualidade.

Flexibilidade para mudanças frente às demandas da atualidade.

Material didático específico do SESI com metodologia adequada à concepção de educação e objetivos.

Remuneração salarial acima da média do mercado para o setor.

\section{Fraquezas}

Pouco tempo destinado à discussão coletiva com as equipes, devido não ter estrutura oferecida pela própria rede para isso.

Inexistência do trabalho de reforço escolar no contra turno.

Objetivos, metas e estratégias

\begin{tabular}{|c|c|c|}
\hline Objetivos & Metas & Estratégias \\
\hline $\begin{array}{l}\text { Desenvolver as competências dos } \\
\text { Coordenadores pedagógicos para que } \\
\text { possam atuar no acompanhamento das } \\
\text { práticas docentes, realizando } \\
\text { intervenções que resultem em melhorias } \\
\text { na aprendizagem dos educandos. }\end{array}$ & $\begin{array}{l}\text { Acompanhar pelo menos } \\
50 \% \text { dos professores em } \\
\text { cada semestre letivo. }\end{array}$ & $\begin{array}{c}\text { - Atender individualmente os Coordenadores a } \\
\text { partir de pauta estabelecida. } \\
\text { - Realizar encontros mensais com o grupo de } \\
\text { Coordenadores para estudos. } \\
\text { - Oferecer grupos de compartilhamento de } \\
\text { conhecimento virtual, para trocas de saberes. } \\
\text { - Dividir grupos de estudo por interesse temático } \\
\text { e/ou necessidades formativas. } \\
\text { - Analisar os registros e produções. } \\
\text { - Tematizar a prática }\end{array}$ \\
\hline $\begin{array}{l}\text { Contribuir para a melhoria da } \\
\text { aprendizagem dos alunos. }\end{array}$ & $\begin{array}{l}\text { Diminuir em } 30 \% \text { ao longo da } \\
\text { realização do projeto, o } \\
\text { número de alunos no nível } \\
\text { abaixo do básico e básico. }\end{array}$ & $\begin{array}{l}\text { - Capacitar os professores para análise dos } \\
\text { resultados e para a identificação das habilidades } \\
\text { adquiridas pelos alunos, buscando estratégias } \\
\text { de ensino que auxiliem a aprendizagem de todos } \\
\text { os alunos. } \\
\text { - Acompanhar o trabalho dos professores } \\
\text { apoiando sua ação e intervindo para que } \\
\text { obtenham melhores resultados. }\end{array}$ \\
\hline
\end{tabular}




\section{Acompanhamento dos resultados}

Haverá um acompanhamento por parte do Supervisor Técnico Educacional das ações formativas realizadas pelo Coordenador Pedagógico e pelo Analista Técnico Educacional.

Serão feitas orientações verbais e escritas sobre as necessidades de aperfeiçoamento do trabalho, visando 0 redirecionando das ações quando necessário.

O acompanhamento será feito da seguinte forma:

- Análise dos roteiros e rol de critérios elaborados e realização de intervenções para melhorias.

- Verificação do atendimento das metas de acompanhamento da prática docente.

- Verificação da qualidade do acompanhamento da prática docente (análise de projetos formativos, devolutivas, atas).

- Monitoramento do trabalho do Coordenador pedagógico e Analistas Técnicos através de análise dos registros reflexivos de sua prática e também dos resultados das aprendizagens das escolas.

- Análise de formulários: roteiro de observação de aula, coleta de dados, planejamento, etc.

- Observação e avaliação de forma criteriosa do desempenho dos diferentes profissionais.

- Análise dos resultados dos alunos através dos boletins das avaliações externas.

\section{Recursos necessários}

\begin{tabular}{|c|c|c|}
\hline O que vou precisar & Descrição & Como obter \\
\hline $\begin{array}{l}\text { Materiais para a realização das } \\
\text { formações: } \\
\text { - } \quad \text { equipamentos como } \\
\text { projetores, telas de projeção, } \\
\text { caixas de som, notebooks, } \\
\text { suporte flip chart; } \\
\text { - materiais diversos como } \\
\text { apostilas, folhas para flip chart, } \\
\text { canetas, pastas, etc; }\end{array}$ & $\begin{array}{l}\text { Para a realização das formações serão } \\
\text { utilizados alguns recursos que tornarão as } \\
\text { reuniões mais dinâmicas e produtivas. } \\
\text { Serão organizados de acordo com os } \\
\text { planejamentos elaborados por cada } \\
\text { formador e atendendo às necessidades de } \\
\text { cada grupo. }\end{array}$ & $\begin{array}{l}\text { Recursos obtidos via Edital } \\
\text { Projetos Inovadores em } \\
\text { Educação, verba prevista para } \\
\text { despesas de capital e material } \\
\text { de consumo. }\end{array}$ \\
\hline $\begin{array}{l}\text { Verba para a locomoção e } \\
\text { participação nas formações. }\end{array}$ & $\begin{array}{l}\text { Haverá o deslocamento de alguns } \\
\text { profissionais para a participação em } \\
\text { encontros formativos por área de } \\
\text { conhecimento, programados pelos } \\
\text { Analistas Técnicos no caso dos } \\
\text { Professores e pelo Supervisor Técnico no } \\
\text { caso dos Coordenadores Pedagógicos. }\end{array}$ & $\begin{array}{l}\text { Recursos obtidos via Edital } \\
\text { Projetos Inovadores, verba } \\
\text { prevista para locomoção. }\end{array}$ \\
\hline $\begin{array}{l}\text { Recursos humanos: Supervisor } \\
\text { Técnico e Analistas Técnicos }\end{array}$ & $\begin{array}{c}\text { Para a realização das formações os } \\
\text { profissionais responsáveis serão o } \\
\text { Supervisor Técnico e os Analistas Técnicos }\end{array}$ & $\begin{array}{c}\text { Fazem parte da equipe da SEA } \\
\text { de Americana }\end{array}$ \\
\hline Salas para as formações & $\begin{array}{l}\text { Nos dias das capacitações serão utilizadas } \\
\text { salas do Centro Educacional. }\end{array}$ & $\begin{array}{l}\text { Salas da escola onde a SEA } \\
\text { esta instalada - CE SESI } 101 \\
\text { de Americana. }\end{array}$ \\
\hline
\end{tabular}




\section{Marketing e comunicação}

O projeto FOCO NA FORMAÇÃO é de grande relevância, pois além de partir de um conhecimento prévio dos clientes a que se propõe, visa atender a suas necessidades e expectativas, as quais já foram levantadas através de questionários, entrevistas e observações.

Consiste em uma prestação de serviço para a formação continuada de Coordenadores Pedagógicos e Professores das unidades escolares e trará um diferencial muito grande, para 0 alcance de melhorias nos resultados das aprendizagens dos alunos, visto que parte desse conhecimento prévio da clientela e com objetivos bem definidos.

FOCO NA FORMAÇÃO pretende fixar para o seu público-alvo uma imagem de formação voltada para a reflexão na ação e para a ação. Diferencia-se de outras formações que pretendem apenas a transmissão de conceitos prontos, na medida em que propõe um trabalho dialógico e reflexivo sobre o cotidiano escolar e as práticas docentes. Assim, apresenta ações para atender as necessidades e interesses desse público, com 0 objetivo de desenvolver e oferecer esse serviço que com certeza representará um benefício tanto para a unidade quanto para os alunos nela atendidos.

O projeto foi criado e sua divulgação será realizada através do composto de marketing conforme a descrição a seguir:

Serviço - Os cursos e acompanhamento pedagógico serão oferecidos atendendo as especificidades de cada unidade escolar, atendendo as suas necessidades e mantendo um padrão de qualidade sempre presente nas ações do SESI - SP.

Espera-se uma elevação dos resultados das unidades atendidas, através da ampliação do acompanhamento do processo educativo pelo Coordenador Pedagógico e de uma prática docente mais eficaz.

Preço - Os custos do serviço serão mantidos com os recursos obtidos via Edital Projetos Inovadores e verbas do SESI - SP, para os valores de contrapartida.

Praça - As unidades terão atendimento de profissionais em seu próprio local de trabalho, sendo que 0 Supervisor Técnico acompanhará o trabalho do Coordenador Pedagógico e os Analistas Técnicos acompanharão os docentes. Os cursos coletivos para ambos, acontecerão na Supervisão Estratégica de Atendimento de Americana que fica em local de fácil acesso para as unidades escolares. Para a locomoção até o local da formação os funcionários terão reembolso de despesas ou condução fornecida pela entidade.

Promoção - A comunicação do serviço oferecido será feita utilizando várias estratégias:

- Encaminhamento do projeto para as instâncias superiores do SESI - SP para conhecimento e validação.

- Divulgação do projeto no Encontro Saber em Ação, que conta com a participação de praticamente todos os educadores da rede, onde serão apresentados seus objetivos e sua estrutura, estimulandose 0 envolvimento e comprometimento dos envolvidos;

- Marketing direto na página de cada funcionário na intranet, com informações direcionadas a cada segmento, onde terão também a oportunidade de fazer as inscrições para os cursos;

- Os demais funcionários da escola, os alunos e seus pais também ficarão informados sobre o projeto através de cartazes e comunicados que serão disponibilizados nos murais das escolas ou jornais internos.

Processos - Os processos que fazem parte do projeto FOCO NA FORMAÇÃO estão detalhados no item 6.2 .

Alguns processos que envolvem o trabalho do Coordenador Pedagógico deverão ser padronizados e serão definidos e sistematizados com a participação deles. São eles: observação de aulas; análise de materiais de alunos, de planos docentes e de diários de classe; mapeamento e monitoramento dos resultados dos alunos; apresentação de devolutivas aos docentes. 
Pessoas - O projeto contará com a equipe da Supervisão Estratégica de Atendimento de Americana, sendo - Supervisor Técnico Educacional e os Analistas Técnicos Educacionais de $1^{\circ}$ ao $5^{\circ}$ anos, Linguagens, Ciências Humanas, Ciências da Natureza e Matemática para a sua realização. A formação dos Analistas para a condução que lhes cabe será realizada pelo Supervisor Técnico, conforme descrito no projeto

\section{Organização e gerência do empreendimento}

\section{Equipe gestora}

O projeto FOCO NA FORMAÇÃO será coordenado e organizado pela equipe da Supervisão Estratégica de Atendimento de Americana, que se encontra capacitada para executar as ações aqui idealizadas, conforme descrito na tabela abaixo:

\section{Tabela 4}

\section{Equipe gestora}

\begin{tabular}{|c|c|c|}
\hline Função & Formação / Experiência & Principais atividades no projeto \\
\hline $\begin{array}{l}\text { Supervisora } \\
\text { Educacional }\end{array}$ & $\begin{array}{l}\text { Graduação em Pedagogia, Pós- } \\
\text { graduação Lato Sensu em } \\
\text { Psicopedagogia e MBA Gestão } \\
\text { Empreendedora. Iniciou como } \\
\text { Professora de Educação Infantil no } \\
\text { SESI, foi Coordenadora por } 7 \text { anos } \\
\text { e Supervisora de Ensino durante } \\
12 \text { anos. Assumiu esse cargo na } \\
\text { reestruturação ocorrida na } \\
\text { instituição. }\end{array}$ & $\begin{array}{l}\text { Planejar, executar e controlar } 0 \\
\text { projeto. } \\
\text { Realizar as ações formativas } \\
\text { diretamente com os Coordenadores } \\
\text { Pedagógicos. Acompanhar as } \\
\text { ações realizadas pelos Analistas } \\
\text { Técnicos com os docentes. }\end{array}$ \\
\hline $\begin{array}{lr}\text { Analista } & \text { Técnico } \\
\text { Educacional } & \text { de } \\
\text { Ciências Humanas } & \end{array}$ & $\begin{array}{l}\text { Graduação em História. Professor } \\
\text { desta disciplina desde agosto de } \\
2007 \text { e na entidade desde agosto } \\
\text { de } 2008 \text {. Passou a exercer o cargo } \\
\text { de Analista Técnico no início deste } \\
\text { ano com a implantação da } \\
\text { Supervisão Estratégica. }\end{array}$ & $\begin{array}{l}\text { Planejar e executar as ações de } \\
\text { formação continuada com os } \\
\text { docentes. }\end{array}$ \\
\hline $\begin{array}{lr}\text { Analista } & \text { Técnico } \\
\text { Educacional } & \text { de } \\
\text { Ciências da Natureza e } \\
\text { Matemática }\end{array}$ & $\begin{array}{l}\text { Graduação em Ciências com } \\
\text { Habilitação em Química. } \\
\text { Especialização em Ensino de } \\
\text { Química. Professor no Ensino } \\
\text { fundamental, médio técnico e } \\
\text { superior de agosto/2006 a } \\
\text { dezembro/2008. Analista Técnico } \\
\text { Educacional desde janeiro de 2011, } \\
\text { a princípio trabalhando na sede do } \\
\text { SESI em São Paulo, transferindo- } \\
\text { se para Americana na implantação } \\
\text { da SEA. }\end{array}$ & $\begin{array}{l}\text { Planejar e executar as ações de } \\
\text { formação continuada com os } \\
\text { docentes. }\end{array}$ \\
\hline $\begin{array}{lr}\text { Analista } & \text { Técnico } \\
\text { Educacional } & \text { de } \\
\text { Linguagens } & \end{array}$ & $\begin{array}{l}\text { Graduação em Letras. Mestrado } \\
\text { em Linguística concluído e } \\
\text { Doutorado em andamento. } \\
\text { Professor de EJA e de Língua } \\
\text { Portuguesa desde } 2007 \text { e } \\
\text { Formador do Pacto Nacional pela } \\
\text { Alfabetização na Idade Certa, } \\
\text { desde o início deste ano. Assumiu } \\
\text { o cargo de Analista Técnico } \\
\text { Educacional no mês de junho. }\end{array}$ & $\begin{array}{l}\text { Planejar e executar as ações de } \\
\text { formação continuada com os } \\
\text { docentes. }\end{array}$ \\
\hline
\end{tabular}


Analista Técnico $\quad$ Graduação em Ciências com $\mid$ Planejar e executar as ações de

Educacional de $1^{\circ}$ ao $5^{\circ}$ Habilitação em Matemática e formação continuada com os anos

Pedagogia. Pós-graduação Lato docentes.

Sensu em Matemática para Professores de $1^{\circ}$ e $2^{\circ}$ graus e Pósgraduação Lato Sensu em Informática em Educação. Professor desde fevereiro de 1993 e na entidade desde agosto de 2000. Lecionou de $1^{\circ}$ ao $5^{\circ}$ anos, a disciplina de Matemática de $6^{\circ}$ ao $9^{\circ}$ anos, na EJA e como Professor de Informática. Passou a exercer 0 cargo de Analista Técnico no início deste ano com a implantação da Supervisão Estratégica.

A equipe da SEA de Americana tem se preparado através de estudos sistemáticos, além de aproveitar momentos de reflexão e discussão em grupo para o fortalecimento do embasamento teórico e a preparação para a atuação junto às equipes das unidades escolares.

Conta também com o apoio dos Analistas Técnicos que trabalham na sede do SESI em São Paulo para a capacitação dos Analistas locais, aprofundando e aperfeiçoando as suas pautas de formação.

\section{Principais processos}

Os principais processos de trabalho necessários para a realização do projeto, bem como o perfil da equipe, estão representados na tabela abaixo:

\section{Tabela 5}

\section{Processos}

\begin{tabular}{|c|c|c|}
\hline $\begin{array}{l}\text { PROCESSOS DO SEU } \\
\text { EMPREENDIMENTO }\end{array}$ & $\overline{\text { COLABORADOR }}$ & PERFIL NECESSÁRIO \\
\hline $\begin{array}{c}\text { Preparar as reuniões de } \\
\text { capacitação dos Coordenadores } \\
\text { Pedagógicos. } \\
\text { Acompanhar o trabalho in loco } \\
\text { nas unidades escolares } \\
\text { realizando intervenções. }\end{array}$ & $\begin{array}{c}\text { Supervisor Técnico } \\
\text { Educacional }\end{array}$ & $\begin{array}{l}\text { Conhecimento: Diretrizes, concepção, } \\
\text { metodologia, visão, missão - expressos nos } \\
\text { documentos do SESI; } \\
\text { Diretrizes curriculares EF e EM; } \\
\text { Diferentes teorias de ensino e aprendizagem; } \\
\text { Teorias e estratégias de formação de } \\
\text { educadores em serviço; } \\
\text { Habilidade - Capacidade de: } \\
\text { - } \quad \text { planejar e organizar; } \\
\text { - } \quad \text { relacionar princípios, teorias e } \\
\text { normas legais em situações reais; } \\
\text { - } \quad \text { realizar comunicação clara, objetiva } \\
\text { - } \quad \text { precisa; } \\
\text { analisar dados com sabedoria e } \\
\text { reflexão, aplicados a tomada de } \\
\text { decisão; } \\
\text { articular e monitorar produções in } \\
\text { - } \quad \text { loco e a distância; } \\
\quad \text { coletar dados que subsidiem a } \\
\text { implementação de diferentes } \\
\text { processos; } \\
\quad \text { analisar e usar os diferentes }\end{array}$ \\
\hline
\end{tabular}




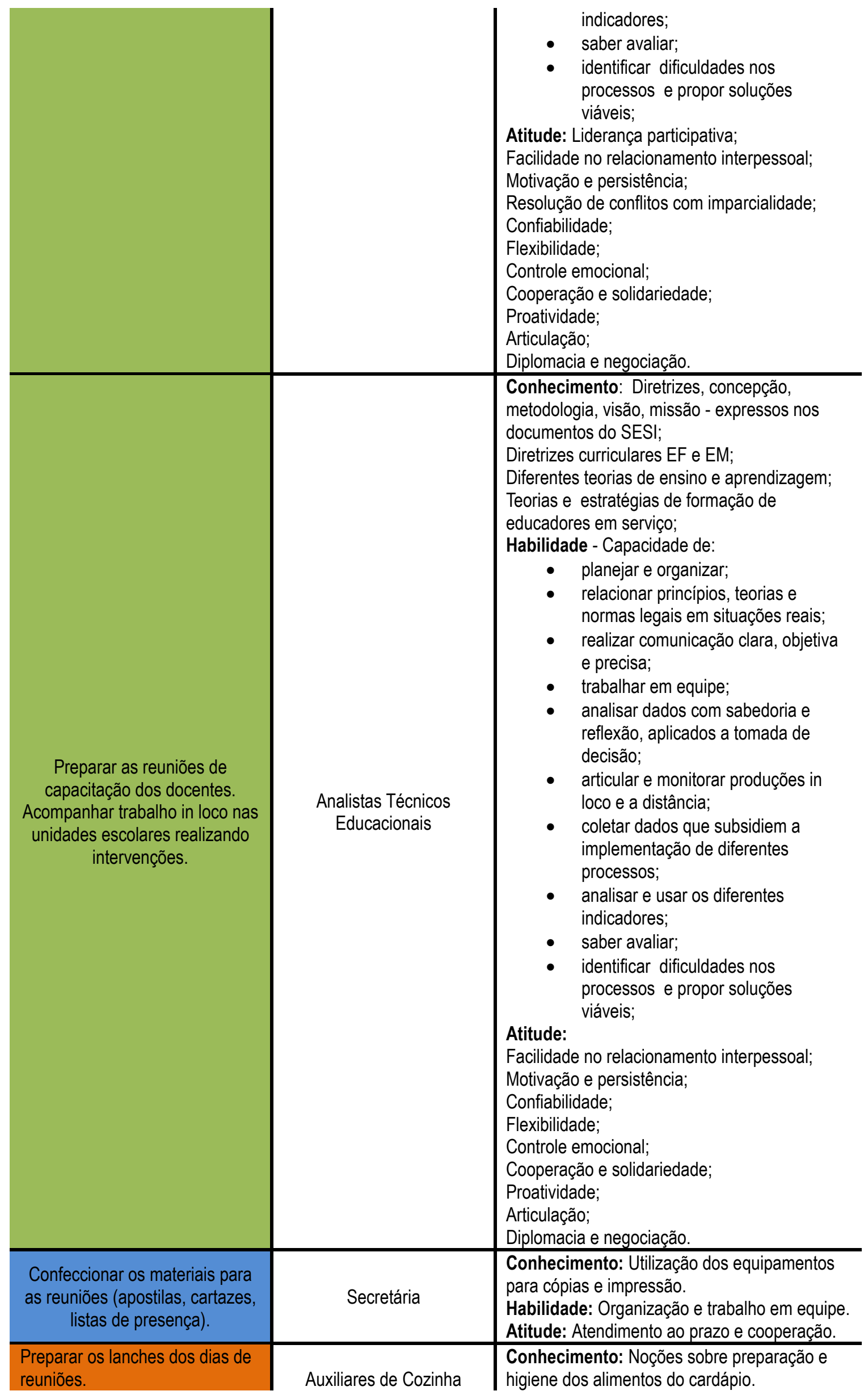

Proatividade;

Diplomacia e negociação

Conhecimento: Diretrizes, concepção,

metodologia, visão, missão - expressos nos

Diferentes teorias de ensino e aprendizagem

Teorias e estratégias de formação de

educadores em serviço;

ilidade - Capacidade de:

- planejar e organizar

relacionar princípios, teorias e mas legais em situações reais;

realizar comunicação clara, objetiva e precisa

trabalhar em equipe

analisar dados com sabedoria e reflexão, aplicados a tomada de

Preparar as reuniões de capacitação dos docentes. Acompanhar trabalho in loco nas intervenções.
Analistas Técnicos

Educacionais

Auxiliares de Cozinha 


\begin{tabular}{|c|c|c|}
\hline & & $\begin{array}{l}\text { Habilidade: Organização e trabalho em equipe. } \\
\text { Atitude: Atendimento ao prazo e cooperação. }\end{array}$ \\
\hline $\begin{array}{c}\text { Garantir a limpeza das } \\
\text { dependências que serão usadas } \\
\text { para a formação }\end{array}$ & Auxiliares de Conservação & $\begin{array}{l}\text { Conhecimento: Noções de limpeza e } \\
\text { manipulação dos produtos e utensilios. } \\
\text { Habilidade: Organização e trabalho em equipe. } \\
\text { Atitude: Facilidade no relacionamento } \\
\text { interpessoal, cooperação e agilidade. }\end{array}$ \\
\hline
\end{tabular}

Legenda:

\begin{tabular}{|l|}
\hline Processo Pedagógico \\
\hline Processo Administrativo \\
\hline Processo de Apoio \\
\hline
\end{tabular}

\section{Plano financeiro}

Para o desenvolvimento do projeto FOCO NA FORMAÇÃO, o plano financeiro encontra-se detalhado abaixo.

\section{Tabela 6}

\section{Investimentos (despesas de capital)}

\begin{tabular}{c|c|c|c}
\multicolumn{1}{c|}{ Item } & Ano1 & Ano2 & Ano3 \\
\hline Obras e infraestrutura & $\mathbf{0 , 0 0}$ & $\mathbf{0 , 0 0}$ & $\mathbf{0 , 0 0}$ \\
\hline Material permanente & & & $\mathbf{0 , 0 0}$ \\
\hline Projetores multimídia & $13.725,20$ & 0,00 & 0,00 \\
\hline Telas para projeção & $7.196,00$ & 0,00 & 0,00 \\
\hline Caixas de som & 623,20 & 0,00 & 0,00 \\
\hline Notebooks & 156,00 & 0,00 & 0,00 \\
\hline Suportes para folha flip chart & $5.560,00$ & 0,00 & 0,00 \\
\hline Total & 158,00 & & $\mathbf{0 , 0 0}$
\end{tabular}

Tabela 7

\section{Detalhamento no quadro abaixo}

\begin{tabular}{l|c|c|c}
\multicolumn{1}{c|}{ Descrição } & Quantidade & Custo Unit. (R\$) & $\begin{array}{c}\text { Total } \\
\text { (R\$) }\end{array}$ \\
\hline Projetores Multimídia - Epson S12 & 4 & $1.799,00$ & $7.196,00$ \\
\hline $\begin{array}{l}\text { Telas para projeção brancas TTM 180 S } \\
\text { TT029 TES }\end{array}$ & 4 & 155,80 & 623,20 \\
\hline $\begin{array}{l}\text { Caixas de som 2.0 - 4W - Rms Mini Black } \\
\text { Mini }\end{array}$ & 4 & 39,00 & 156,00 \\
\hline Notebooks HP Pavilion G4 - 1130 Core 1.3 & 4 & $1.390,00$ & $5.560,00$ \\
\hline $\begin{array}{l}\text { Suportes para folha flip chart - Criarte em } \\
\text { duratex }\end{array}$ & 4 & 39,50 & 158,00 \\
\hline
\end{tabular}




\section{Despesas correntes}

Relacionadas no quadro abaixo as despesas correntes que farão parte da manutenção do projeto FOCO NA FORMAÇÃO.

Tabela 8

\section{Despesas correntes}

\begin{tabular}{|c|c|c|c|}
\hline \multicolumn{4}{|c|}{ Projeção das Despesas Correntes } \\
\hline Material de Consumo & Total ANO 1 & Total ANO 2 & Total ANO 3 \\
\hline Folhas de papel para flip chart & 202,80 & 216,99 & 232,18 \\
\hline Papel sulfite Oficio A-4 & 309,60 & 331,27 & 354,46 \\
\hline Canetas & 240,00 & 256,80 & 274,77 \\
\hline Lanches & $9.600,00$ & $10.272,00$ & $10.991,04$ \\
\hline Total & $10.352,40$ & $11.077,06$ & $11.854,45$ \\
\hline Passagens e Locomoção & Total ANO 1 & Total ANO 2 & Total ANO 3 \\
\hline Locação de ônibus & $9.600,00$ & $10.368,00$ & $11.197,44$ \\
\hline Total & $9.600,00$ & $10.368,00$ & $11.197,44$ \\
\hline Serviços de Terceiros & Total ANO 1 & Total ANO 2 & Total ANO 3 \\
\hline Manutenção & $1.800,00$ & $1.944,00$ & $2.099,52$ \\
\hline Cópia de xerox & $1.800,00$ & $1.926,00$ & $2.060,82$ \\
\hline Total & $3.600,00$ & $3.870,00$ & $4.160,34$ \\
\hline Total das Despesas Correntes & $23.552,40$ & $25.315,06$ & $27.212,23$ \\
\hline
\end{tabular}

\section{Detalhamento:}

- Um bloco de folhas de papel para flip chart, valor unitário $\mathrm{R} \$ 16,90$;

- Duas resmas de papel sulfite, valor unitário R\$12,90;

- Uma caixa de canetas esferográficas, valor $\mathrm{R} \$ 20,00$

- Lanche para os participantes do curso, valor $\mathrm{R} \$ 800,00$.

- Transporte em ônibus fretado no valor de $\mathrm{R} \$ 9.600,00$ por ano.

- Manutenção dos equipamentos no valor de $\mathrm{R} \$ 1.800,00$ anual.

- Cópias de xerox para as apostilas de formação no valor de $\mathrm{R} \$ 1.800,00$ anual.

\section{Despesas administrativas e de pessoal}

Relacionadas no quadro abaixo as despesas administrativas que farão parte da manutenção do projeto FOCO NA FORMAÇÃO 
Tabela 8

\section{Despesas Administrativas e de Pessoal}

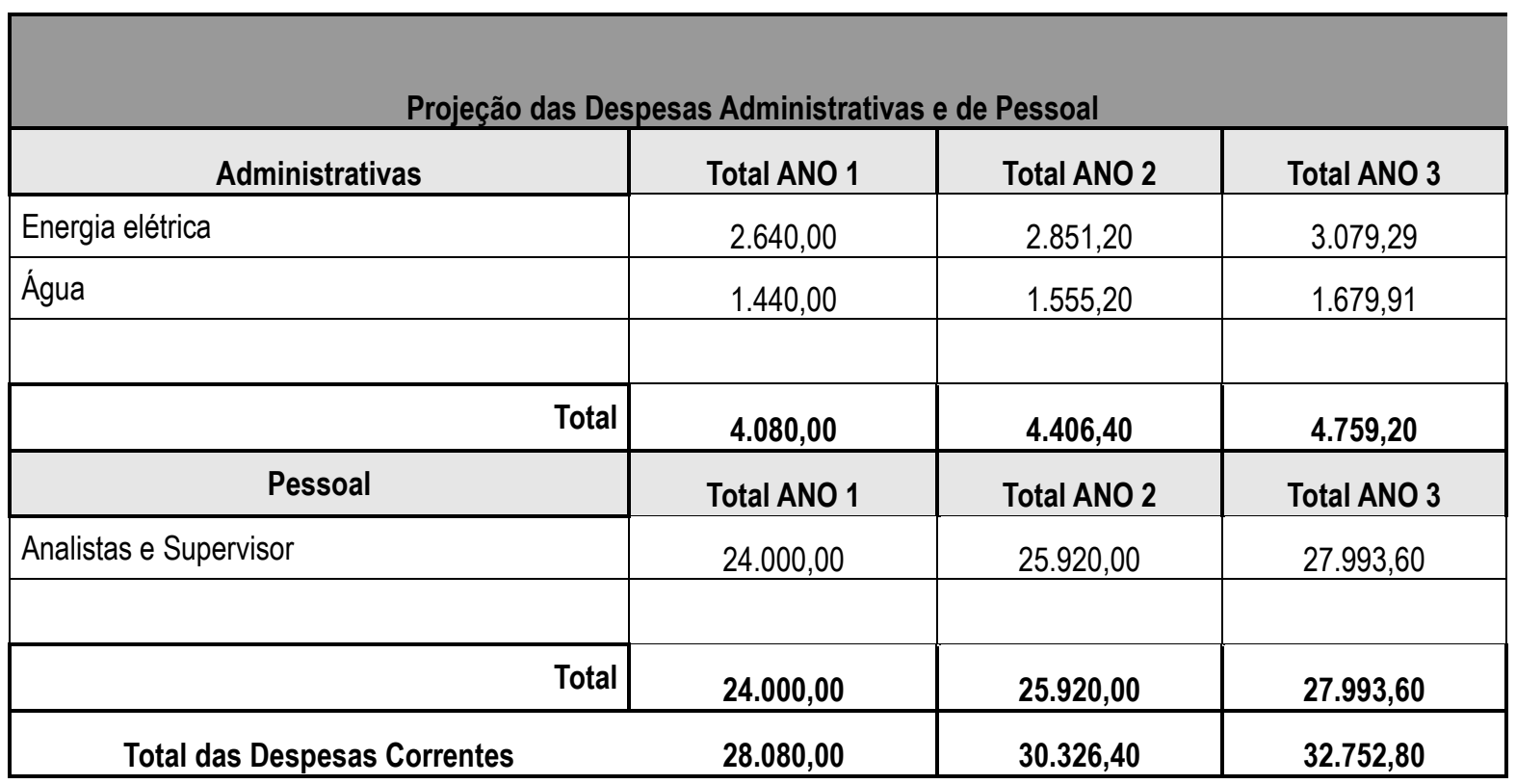

\section{Necessidade de recursos}

Abaixo apresentado o quadro com a síntese do cálculo das necessidades de recursos para a implantação e manutenção do projeto FOCO NA FORMAÇÃO. Nele constam as necessidades de investimento ou Despesas de Capital, as Despesas Correntes, Despesas Administrativas e Despesas com pessoal.

\section{Tabela 9}

\section{Síntese das necessidades de recursos}

\begin{tabular}{|c|c|c|c|c|}
\hline \multicolumn{4}{|c|}{ Cálculo da Necessidade de Recursos } & \multirow[b]{2}{*}{ TOTAL } \\
\hline Item & ANO 1 & ANO 2 & ANO 3 & \\
\hline I. Total das Despesas Correntes & $23.552,40$ & $25.315,07$ & $27.210,24$ & \multirow{4}{*}{$\begin{array}{l}76.077,71 \\
33.281,93 \\
31.165,44 \\
11.630,34\end{array}$} \\
\hline Material de Consumo & $10.352,40$ & $11.077,07$ & $11.852,46$ & \\
\hline Passagens e Despesas com Locomoção & $9.600,00$ & $10.368,00$ & $11.197,44$ & \\
\hline Serviços de Terceiros & $3.600,00$ & $3.870,00$ & $4.160,34$ & \\
\hline II. Total de Despesas Administrativas & $4.080,00$ & $4.406,40$ & $4.758,91$ & \multirow{3}{*}{$\begin{array}{l}13.245,31 \\
77.913,60 \\
13.725,20 \\
\end{array}$} \\
\hline III. Total de Despesas com Pessoal & $24.000,00$ & $25.920,00$ & $27.993,60$ & \\
\hline $\begin{array}{l}\text { IV. Total de Despesas de Capital } \\
\text { (investimentos) }\end{array}$ & $13.725,20$ & 0,00 & 0,00 & \\
\hline Necessidade de Recursos (|+||+|II+|V) & $65.357,60$ & $55.641,47$ & $59.962,75$ & $180.961,82$ \\
\hline Recursos Edital & $37.277,60$ & $25.315,07$ & $27.210,24$ & $89.802,91$ \\
\hline Recursos da Organização (contrapartida) & $28.080,00$ & $30.326,40$ & $32.752,51$ & $91.158,91$ \\
\hline
\end{tabular}


Heliana Battaglia Beltrame

\section{Referências Bibliográficas}

POZO, J.I. Aprendices y maestros. Madri: Aliança/Psiclogia Minor, 1996. 